\title{
Parasit gastrointestinal pada Domba Ekor Gemuk di Kabupaten Jember
}

\section{Gastrointestinal parasites in fat-tailed sheep in Jember district}

Aan Awaludin ${ }^{1 *}$, Agustinus Gede Nyoman Mariyanto' ${ }^{1}$, Nurkholis ${ }^{1}$, Suci Wulandari $^{1}$, Suluh Nusantoro', Nur Muhamad', M. Adhyatma1, Rizki Amalia Nurfitriani ${ }^{1}$, Theo Mahiseta Syahniar ${ }^{1}$, Gayuh Syaikhullah ${ }^{2}$, Mira Andriani $^{2}$, dan Yudhi Ratna Nugraheni ${ }^{3}$

${ }^{1}$ Program Studi Produksi Ternak, Jurusan Peternakan, Politeknik Negeri Jember, Jl. Mastrip 164, Jember 68121

${ }^{2}$ Program Studi Manajemen Bisnis Unggas, Jurusan Peternakan, Politeknik Negeri Jember, Jl. Mastrip 164, Jember, 68121

${ }^{3}$ Departemen Parasitologi, Fakultas Kedokteran Hewan, Universitas Gadjah Mada, Jl. Fauna No. 2, Sleman 55281

*Email Koresponden: aanawaludin@polije.ac.id

Abstrak. Tujuan penelitian adalah untuk mengidentifikasi parasit gastrointestinal yang menginfeksi saluran pencernaan pada Domba Ekor Gemuk di kabupaten Jember. Penelitian ini menggunakan sampel feses segar dari 50 ekor Domba Ekor Gemuk di kabupaten Jember. Pengambilan sampel secara acak dengan tidak membedakan jenis kelamin dan umur Domba Ekor Gemuk. Identifikasi parasit gastrointestinal dengan menggunakan uji apung (flotation methods) kemudian dilakukan pengamatan morfologi telur cacing dan oosista yang ditemukan pada sampel feses Domba Ekor Gemuk. Hasil identifikasi adalah ditemukannya parasit gastrointestinal pada Domba Ekor Gemuk di kabupaten Jember dari kelas nematoda dan protozoa. Parasit cacing kelas nematoda yang teridentifikasi adalah Strongyloides sp., Cooperia sp., Moniezia sp., Capillaria sp., dan Ostertagia sp., sedangkan protozoa yang teridentifikasi adalah Eimeria sp. Prevalensi parasit gastrointestinal didominasi oleh Strongyloides $\mathrm{sp}$. $(20 \%)$, Eimeria sp. (8\%), Moniezia sp. (8\%), Capillaria sp. (4\%), Cooperia sp. $(2 \%)$, dan Ostertagia sp. (2\%). Kejadian infeksi murni atau infeksi tunggal (single infections) sebanyak $95 \%$ dan infeksi campuran (co-infections) sebanyak 5\%.

Kata kunci: cacing, domba, gastrointestinal, oosista, parasit

Abstract. The aim of the study was to identify gastrointestinal parasites that infect the digestive tract of Fat Tailed Sheep in Jember Regency. This study used fresh faecal samples from 50 Fat Tailed Sheep in Jember district. Sampling was carried out randomly without discriminating between sex and age of Fat Tailed Sheep. Identification of gastrointestinal parasites by using the flotation method and then observing the morphology of the eggs of worms and oocysts found in the faecal samples of Fat Tailed Sheep. The result of the identification was the finding of gastrointestinal parasites in Fat Tailed Sheep in Jember Regency from the class of nematodes and protozoa. The worm parasites of the nematode class identified were Strongyloides sp., Cooperia sp., Moniezia sp., Capillaria sp., and Ostertagia sp., while the protozoa identified were Eimeria sp. The prevalence of gastrointestinal parasites was dominated by Strongyloides sp. (20\%), Eimeria sp. (8\%), Moniezia sp. (8\%), Capillaria sp. (4\%), Cooperia sp. (2\%), and Ostertagia sp. (2\%). The incidence of pure infection or single infections is $95 \%$ and co-infections is $5 \%$.

Keywords: worm, sheep, gastrointestinal, oocyst, parasite 
Awaludin et al.

ANIMPRO: Conference of Applied Animal Science Proceeding Series

\section{PENDAHULUAN}

Variasi genetik dari ternak domba di Indonesia sangat beragam, hal tersebut berpengaruh pada fenotip dan karakteristik yang bervariasi baik secara fisik juga kemampuan dalam beradaptasi dengan lingkungan tropis yang sesuai dengan lokasi serta kawasan dalam pengembangannya. Ternak domba di Indonesia terdapat 2 macam yaitu ternak lokal atau asli Indoensia dan ternak impor atau persilangannya (crossbreed), semua kelompok tersebut mampu berkembang dan beradaptasi serta berkembang biak di Indonesia. Domba asli di Indonesia antara lain domba Garut, DEG (domba ekor gemuk), DET (domba ekor tipis), Kisar, Priangan, Sumatera, dan lainlain. Domba impor atau persilangannya antara lain komposit Garut, komposit Sumatera, St Croix Indonesia, Barbados Cross, Dombos (Texel x DET), Batur (Merino x lokal), dan lain-lain (Talib, Matondang, \& Herawati, 2011). Domba merupakan salah satu ternak yang sering dibudidayakan oleh peternak di Indonesia. Budidaya ternak domba diminati oleh peternak karena domba memiliki sifat prolifik yaitu mampu beranak 2 sampai 4 ekor per kelahiran sehingga perkembangbiakannya cepat (Rahayu dkk., 2018).

Salah satu kendala dalam usaha pembangunan di bidang peternakan adalah gangguan kesehatan pada hewan ternak. Infeksi parasit merupakan salah satu penyebab gangguan kesehatan pada hewan ternak, parasit gastrointestinal seperti cacing dan protozoa sering dijumpai pada ternak domba. Infeksi parasit tersebut mempunyai potensi dan mampu menyebabkan penurunan produktifitas dari ternak. Dampak yang diakibatkan karena infestasi cacing pada ternak antara lain mempengaruhi penurunan produktivitas dan daya produksi, penurunan berat badan sampai kejadian kekurusan, serta pada infeksi berat mampu menyebabkan gangguan pencernaan (diare) dan pertumbuhan ternak terhambat (Purwaningsih, Noviyanti, \& Sambodo, 2018). Pada domba yang terinfestasi parasit cacing di saluran pencernaan sering menimbulkan penurunan performa dari produktivitas dan reproduksinya (Ayaz et al., 2013). Infeksi yang disebabkan oleh parasit gastrointestinal mengakibatkan kondisi penyerapan nutrien yang tidak baik sehingga berdampak pada proses pertumbuhan dari ternak menjadi terhambat (Terefe et al., 2012). Infeksi parasit gastrointestinal pada domba bisa mengakibatkan anemia pada kasus infeksi berat (Hassan et al., 2011). Infeksi yang disebabkan oleh parasit cacing (helminthosis) pada domba dan kambing merupakan salah satu infeksi endoparasit yang bertanggung jawab atas kerugian ekonomi dengan menyebabkan penurunan produktivitas dan peningkatan kematian (Perry et al., 2002). Mayoritas penelitian (86\%) melaporkan bahwa kejadian infeksi parasit gastrointestinal menimbulkan efek negatif pada produksi, penurunan produksi wol pada domba, penurunan berat badan, dan penurunan produksi susu (Mavrot, Hertzberg, \& Torgerson, 2015).

Penyakit parasit sering dijumpai pada ternak ruminansia termasuk didalamnya adalah gangguan kesehatan yang disebabkan oleh parasit cacing. Usaha untuk meningkatkan produksi peternakan di bidang kesehatan ternak diperlukan adanya kegiatan sosialisasi, transfer pengetahuan, pengontrolan dan pencegahan penyakit termasuk penyakit yang disebabkan oleh parasit cacing (Awaludin dkk., 2021). Hanafiah, Winaruddin, \& Rusli (2002) dalam penelitiannya juga menjelaskan bahwa parasit cacing dalam saluran pencernaan menjadi salah satu penyakit parasitik yang paling sering diabaikan dan menjadi permasalahan di bidang peternakan. Parasit cacing yang berinfestasi di saluran pencernaan merupakan permasalahan utama penyebab gangguan kesehatan ternak terutama pada ruminansia kecil. Sultan, Elmonir, \& Hegazy (2016), berbagai parasit gastrointestinal ditemukan pada domba diantaranya adalah dari golongan Strongyle, Strongyloides papillosus, Trichuris spp., Paramphistom spp., Nematodirus spp., Moniezia spp., Fasciola spp., dan Eimeria spp. Susilo (2013), melaporkan pada tahun 2011 ternak Domba di Jawa memiliki prevalensi nematodiosis 38\%, strongylodosis $15,92 \%$, dan fasciolosis $29 \%$.

Penelitian ini bertujuan untuk mengidentifikasi parasit gastrointestinal yang ditemukan pada ternak Domba Ekor Gemuk di kabupaten Jember. Domba Ekor Gemuk menjadi salah satu plasma nutfah yang dikembangkan di kabupaten Jember, sehingga perlu adanya evaluasi dan usaha untuk memaksimalkan produktivitas ternak tersebut salah satunya di bidang kesehatan ternak. Identifikasi parasit gastrointestinal pada Domba Ekor Gemuk mempunyai manfaat 
sebagai salah satu sumber data untuk evaluasi program pencegahan dan pengobatan parasit gastrointestinal pada Domba Ekor Gemuk di masa mendatang.

\section{MATERI DAN METODE}

Penelitian dilakukan di kabupaten Jember dengan pengambilan sampel meliputi kecamatan Gumukmas, Wuluhan, Pakusari, Ambulu, dan Bangsal dalam kurun waktu bulan Oktober Desember 2020. Sampel yang diambil sebanyak 50 sampel feses segar dari Domba Ekor Gemuk secara acak dengan tidak menentukan jenis kelamin dan umur dengan masing-masing sampel dikoleksi sebanyak $10 \mathrm{~g}$ dimasukkan ke dalam pot sampel dan diberi label kemudian dimasukkan ke dalam coolbox. Sampel feses yang dikoleksi kemudian dilakukan uji apung (flotation mehods) untuk pengamatan morfologi telur cacing dan oosista yang ditemukan pada sampel feses.

Pengujian dilakukan dengan mengambil $3 \mathrm{~g}$ dari setiap sampel feses kemudian dihaluskan dengan menggunakan mortar. Sampel feses yang sudah dihaluskan ditambah $\mathrm{NaCl}$ sebanyak 30 $\mathrm{ml}$ dan dihomogenkan. Sampel feses dalam larutan $\mathrm{NaCl}$ yang sudah homogen kemudian disaring dan dimasukkan kedalam tabung sentrifus sebanyak $15 \mathrm{ml}$. Sampel feses dalam tabung sentrifus dilakukan sentrifus dengan kecepatan $1.500 \mathrm{rpm}$ selama 5 menit, setelah dilakukan sentrifus kemudian tabung sentrifus tersebut diletakkan pada rak sentrifus dan ditambahkan $\mathrm{NaCl}$ pada permukaannya sampai berbentuk cembung kemudian didiamkan kurang lebih selama 3 menit. Selanjutnya deck glass ditempelkan pada permukaan larutan yang cembung dan diangkat serta diletakkan diatas object glass kemudian dilakukan pengamatan menggunakan mikroskop perbesaran $10 \times 10$.

Telur cacing yang ditemukan kemudian dilakukan identifikasi dengan mengamati dan membandingkan morfologinya serta dibandingkan dengan referensi morfologi telur cacing dari Thienpont, Rochette, \& Vanparijs (1986). Oosista yang ditemukan diidentifikasi dengan merujuk pada referensi dari Urquhat et al., (1987).

\section{HASIL DAN PEMBAHASAN}

Hasil dari pemeriksaan sampel feses Domba Ekor Gemuk di kabupaten Jember dengan metode apung (floating methods) teridentifikasi adanya parasit gastrointestinal dari golongan parasit cacing dan protozoa (Tabel 1).

Tabel 1. Hasil identifikasi parasit gastrointestinal pada Domba Ekor Gemuk di kabupaten Jember. No. Sampel

$3,7,8,9,10,11,12,14,15,16,18,27,28$,

$29,30,31,32,33,35,36,37,38,39,40,41$, Floating methods

$47,48,49,50$

$$
1,2,4
$$

$6,19,20,21,22,23,42,43,46$

$$
13
$$

$17,24,25,26$

34,45

44

5
Negatif

\section{Eimeria sp.}

Strongyloides sp.

Cooperia sp.

Moniezia sp.

Capillaria sp.

Ostertagia sp.

Eimeria sp., Strongyloides sp.

Total sampel feses Domba Ekor Gemuk sebanyak 50 sampel diperoleh hasil 29 sampel feses tidak ditemukan adanya telur cacing maupun oosista atau negatif $(58 \%)$ dan 21 sampel feses ditemukan adanya telur cacing maupun oosista (42\%) (Gambar 1). 
Awaludin et al.

ANIMPRO: Conference of Applied Animal Science Proceeding Series

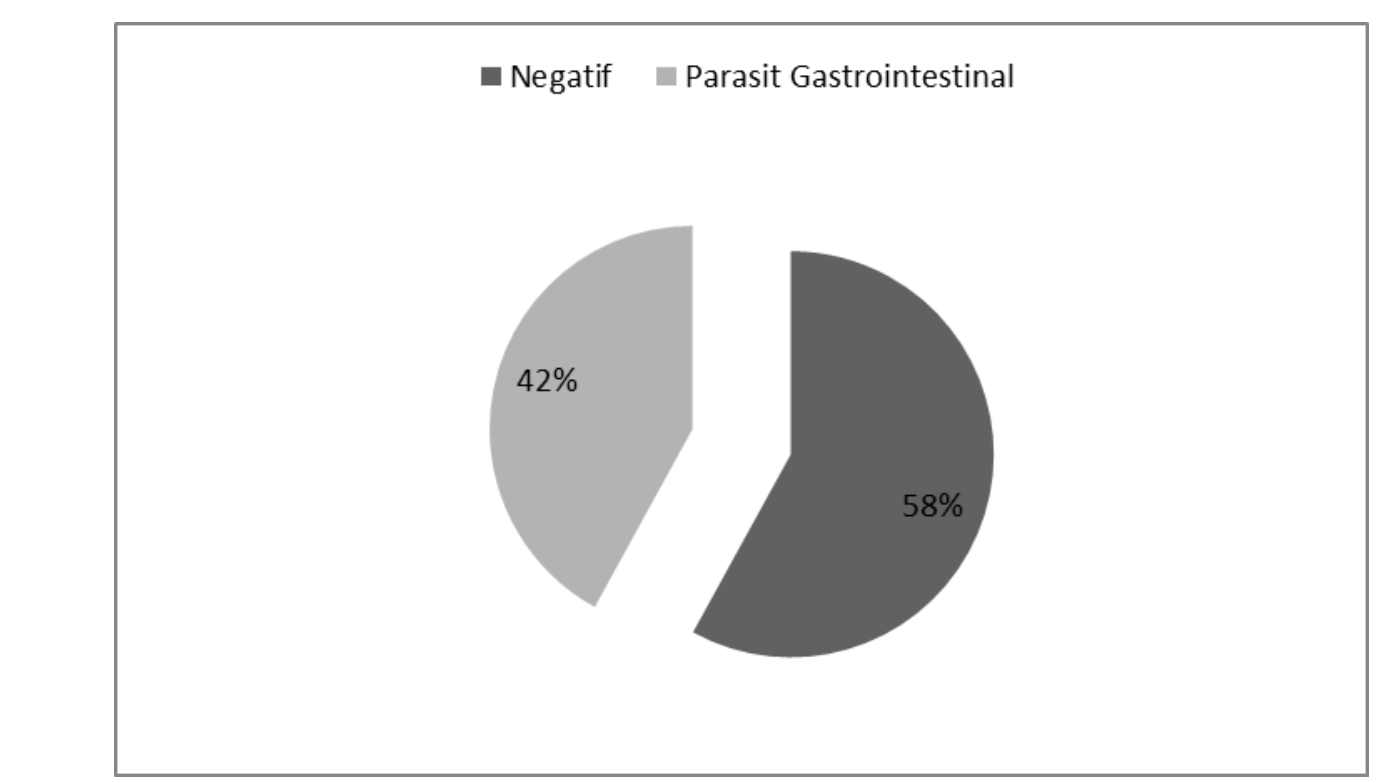

Gambar 1. Prosentase hasil pemeriksaan sampel feses Domba Ekor Gemuk di kabupaten Jember.

Telur parasit cacing yang teridentifikasi pada Domba Ekor Gemuk di kabupaten Jember adalah dari kelas nematoda yaitu dari spesies Strongyloides sp., Cooperia sp., Moniezia sp., Capillaria sp., dan Ostertagia sp. Sampel feses dengan nomor sampel 5, 6, 19, 20, 21, 22, 23, 42, 43, dan 46 teridentifkasi adanya telur cacing Strongyloides sp. dengan morfologi telur berbentuk elips, lebar, mempunyai cangkang tipis dengan tepian halus serta terdapat embrio berwarna abu-abu. Ciri morfologi telur cacing tersebut sesuai dengan morfologi yang dijelaskan oleh Thienpont, Rochette, \& Vanparijs (1986) yaitu Strongyloides sp. mempunyai telur berbentuk elips dan lebar, berembrio dengan warna keabu-abuan, kutub lebar dan sedikit rata, memiliki cangkang tipis dengan permukaan halus. Sampel feses dengan nomor sampel 13 teridentifikasi telur cacing dengan ciri morfologi berbentuk elips kecil, mempunyai kutub kecil, cangkang tipis dengan permukaan halus serta terdapat membran yolk tipis didalamnya, dan mempunyai blastomer dengan junlah banyak. Ciri morfologi tersebut merupakan telur cacing dari Cooperia sp. Thienpont, Rochette, \& Vanparijs (1986) menjelaskan bahwa morfologi dari telur cacing Cooperia sp. adalah berbentuk elips berukuran kecil, pipih, berkutub kecil, cangkang tipis dengan permukaan halus, sisi dalam ditutupi dengan membran yolk tipis, dan terdapat blastomer dengan jumlah sangat banyak. Sampel feses dengan nomor sampel 17, 24, 25, dan 26 ditemukan telur cacing dengan ciri morfologi berbentuk tidak beraturan dengan tepi triangular dan beberapa telur mempunyai tepi quadrangular, setiap sudut tepi membulat, bercangkang tebal dengan permukaan halus serta berwarna gelap keabu-abuan, berisi embrio berbentuk seperti buah pir, menurut Thienpont, Rochette, \& Vanparijs (1986) telur cacing dengan morfologi berbentuk bulat tidak beraturan (triangular atau quadrangular), mempunyai sudut membulat dan dinding melengkung, bercangkang tebal dengan permukaan halus, berwarna abu-abu gelap, berisi embrio yang dikelilingi oleh aparatus piriform (berbentuk buah pir) adalah ciri morfologi dari telur cacing Moniezia sp.

Sampel feses dengan nomor sampel 34 dan 35 mempunyai ciri morfologi berbentuk seperti buah lemon dengan dinding samping hamper sejajar, terdapat 2 kutub dengan sumbat transparan dan menonjol, mempunyai cangkang tebal dan berkerut, unsegmented dan bergranular ciri morfologi tersebut merupakan ciri-ciri dari telur cacing Capillaria sp. seperti ciri morfologi Capillaria sp. yang dijelaskan oleh Thienpont, Rochette, \& Vanparijs (1986) yaitu telur cacing berbentuk buah lemon, berkutub di kedua ujung dengan sumbat transparan dan sedikit menonjol, mempunyai dinding samping yang hampir sejajar, bercangkang tebal, permukaan berkerut, unsegmented dan bergranular. Sampel feses nomor sampel 44 ditemukan telur cacing dengan morfologi berbentuk elips dan simetris, terdapat kutub dengan ukuran sedang dan 
Awaludin et al.

ANIMPRO: Conference of Applied Animal Science Proceeding Series

simetris, dinding samping tipis dan simetris berbentuk barrel-shaped (tong) tipis dan halus, dibagian dalam terdapat membrane yolk tipis dengan sejumlah blastomer yang hampir sama dan berisi penuh. Ciri tersebut merupakan ciri morfologi dari telur cacing Ostertagia sp., sesuai dengan referensi ciri morfologi telur cacing Ostertagia sp. dari Thienpont, Rochette, \& Vanparijs (1986) yaitu berbentuk elips beraturan, simetris, kutub tidak terlalu lebar, dinding samping agak berbentuk berbentuk barrel-shaped, tipis, cangkang chitinous dengan permukaan halus, sisi dalam ditutupi dengan membran yolk, terdapat sejumlah besar blastomer yang sulit dibedakan. Sampel feses dengan nomor sampel 5 disamping ditemukan adanya telur cacing Strongyloides sp. juga ditemukan adanya oosista dengan ciri morfologi berbentuk ovoid, berwarna kuning, terdapat kutub di salah satu ujung dengan mikrofil, berdinding halus. Urquhat et al., (1987) menjelaskan bahwa oosista Eimeria sp. berbentuk bulat-ovoid atau elips dengan permukaan dinding halus dan transparan, mempunyai kutub di salah satu ujung dengan topi mikrofil, umumnya tidak berwarna namun beberapa diantaranya mempunyai warna kuning. Dari ciri morfologi oosista yang ditemukan pada sampel feses dan dibandingkan dengan literature maka dapat disimpulkan bahwa oosista yang ditemukan pada sampel feses bernomor sampel 5 adalah oosista Eimeria sp.

Infestasi parasit yang teridentifikasi pada Domba Ekor Gemuk di kabupaten Jember adalah dari kelas nematoda. Parasit cacing dari kelas nematoda lebih mempunyai potensi penyebaran dan penularan yang lebih luas dibandingkan oleh parasit cacing dari kelas trematoda, karena parasit cacing kelas nematoda memiliki siklus hidup langsung. Sangma et al. (2012) menjelaskan bahwa kejadian infeksi oleh parasit cacing pada saluran pencernaan domba bisa disebabkan oleh parasit cacing dari kelas nematoda, trematoda, ataupun cestoda. Zeryehun (2012) melaporkan bahwa pada domba dan kambing sebaran dari infeksi parasit cacing kelas nematoda adalah yang paling dominan dibandingkan dari kelas trematoda dan cestoda. Oosista Eimeria sp. teridentifikasi pada sampel feses dengan nomor sampel 1, 2, dan 4, meskipun pada Domba Ekor Gemuk sampel tidak menunjukkan gejala klinis koksidiosis yang nyata. Pada kasus infeksi berat Eimeria sp. menyebabkan kerusakan pada sel epitel saluran pencernaan khususnya pada usus halus dan usus besar. Chartier \& Paraud (2011) menjelaskan pada uraian review tentang koksidiosis pada ruminansia kecil, bahwa koksidiosis pada ruminansia kecil bisa disebabkan oleh beberapa spesies dari genus Eimera yang berkembang pada usus halus dan usus besar. Kejadian koksidiosis pada ruminansia kecil mampu memberikan resiko yang mempengaruhi kesehatan ternak khususnya ternak muda. Koksidiosis pada ruminansia kecil sering dijumpai bersifat subklinis dan berjalan kronis sehingga mengganggu pertumbuhan ternak, namun juga bisa terjadi secara klinis sehingga mengakibatkan gangguan kesehatan yang nyata seperti diare sampai diare bercampur darah.

Kejadian infeksi parasit gastrointestinal pada Domba Ekor Gemuk di kabupaten Jember terdiri dari infeksi tunggal (single infections) dan infeksi campuran (co-infections) (Tabel 1). Singleinfections terjadi pada sampel dengan nomor sampel 1,2, dan 4 yang ditemukan adanya oosista Eimeria sp., nomor sampel 6, 19, 20, 21, 22, 23, 42, 43, dan 46 ditemukan telur cacing Strongyloides sp., nomor sampel 13 ditemukan telur cacing Cooperia sp., nomor sampel 17, 24, 25, dan 26 ditemukan telur cacing Moniezia sp., nomor sampel 34 dan 35 ditemukan telur cacing Capillaria sp., serta nomor sampel 44 ditemukan telur cacing Ostertagia sp. Total Domba Ekor Gemuk sampel yang mengalami kejadian single-infections adalah 20 ekor atau 95\% (Gambar 2). Sedangkan Domba Ekor Gemuk sampel yang mengalami kejadian co-infections adalah 1 ekor yaitu pada sampel dengan nomor sampel 5 yang ditemukan adanya oosista Eimeria sp. dan telur cacing Strongyloides sp. atau 5\% (Gambar 2). Zeryehun (2012) menjelaskan bahwa kejadian infeksi parasit gastrointestinal pada ternak domba dan kambing bisa disebabkan oleh dua atau lebih jenis parasit dan juga bisa disebabkan oleh infeksi murni dari 1 spesies parasit. Kumsa et al. (2011) melaporkan bahwa kejadian infeksi campuran oleh parasite gastrointestinal diduga mampu menyebabkan morbiditas yang tinggi sehingga bisa menurunkan bahkan menghentikan kemampuan produksi dari domba dan kambing. 
Awaludin et al.

ANIMPRO: Conference of Applied Animal Science Proceeding Series

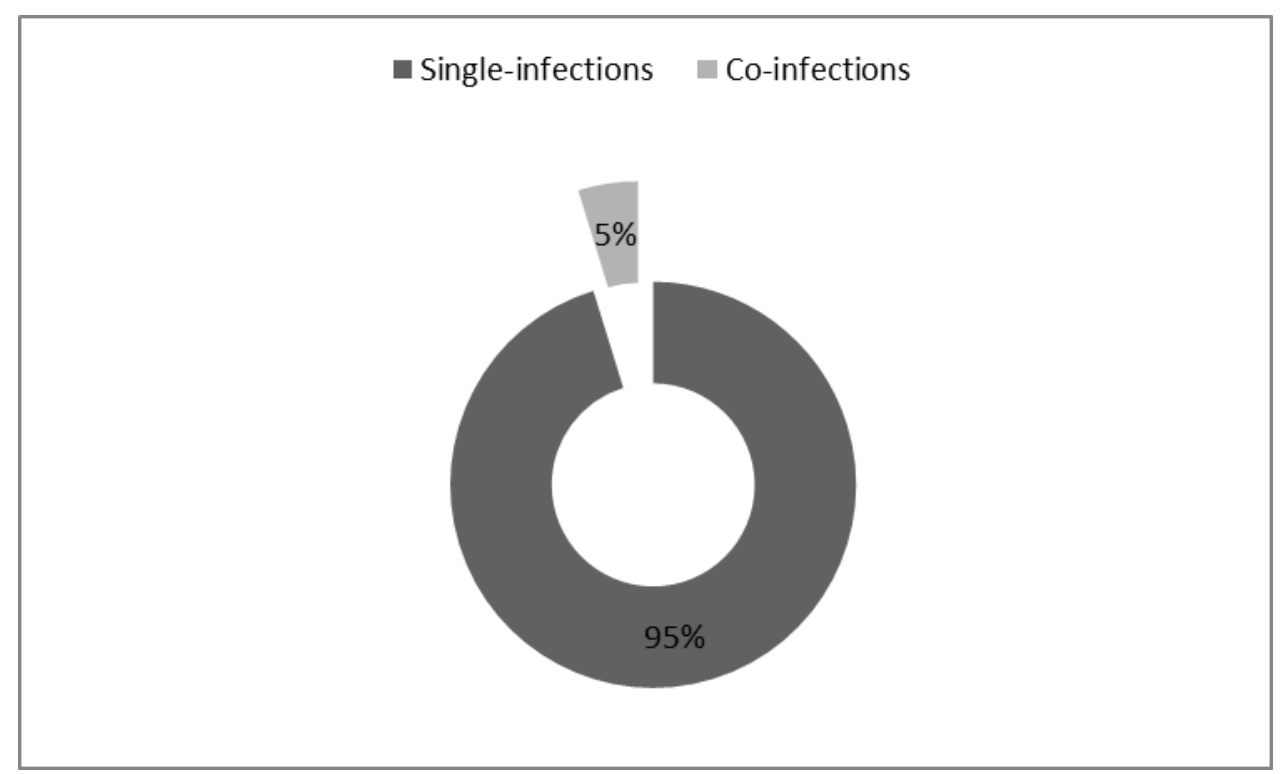

Gambar 2. Jenis infeksi parasit gastrointestinal pada Domba Ekor Gemuk di kabupaten Jember

Prevalensi dari parasit gastrointestinal pada Domba Ekor Gemuk di kabupaten Jember tersaji pada Tabel 2.

Tabel 2. Prevalensi parasit gastrointestinal pada Domba Ekor Gemuk di kabupaten Jember.

\begin{tabular}{ccc}
\hline Jumlah sampel & Parasit Gastrointestinal & Prevalensi $(\%)$ \\
\hline 29 & Negatif & $29 / 50(58,0)$ \\
4 & Eimeria sp. & $4 / 50(8,0)$ \\
10 & Strongyloides sp. & $10 / 50(20,0)$ \\
1 & Cooperia sp. & $1 / 50(2,0)$ \\
4 & Moniezia sp. & $4 / 50(8,0)$ \\
2 & Capillaria sp. & $2 / 50(4,0)$ \\
1 & Ostertagia sp. & $1 / 50(2,0)$ \\
\hline
\end{tabular}

Prevalensi parasit gastrointestinal pada Domba Ekor Gemuk di kabupaten Jember didominasi oleh parasit cacing dari spesies Strongyloides sp. (20\%), kemudian diikuti oleh parasit gastrointestinal dari golongan protozoa yaitu Eimeria sp. (8\%) dan dari parasit cacing spesies Moniezia sp. (8\%), dan seterusnya dari parasit cacing Capillaria sp. (4\%), Cooperia sp. (2\%), dan Ostertagia sp. (2\%). Prevalensi Strongyloides sp. pada penelitian ini sangat dominan dimungkinkan karena pengambilan sampel dilakukan pada musim penghujan (Oktober Desember 2020) sehingga kondisi lingkungan sangat memungkinkan untuk kelangsungan siklus hidup khususnya pada stadium larva infektif dari parasit cacing tersebut. Hal ini berbeda dengan penelitian Awaludin, Nurkholis, Nusantoro (2019) yang melaporkan bahwa kejadian terbanyak parasit gastrointestinal dari kelas nematoda pada musim kemarau (kering) adalah dari spesies Ostertagia sp. Pfukenyi \& Mukaratirwa (2013) menjelaskan bahwa tinggi rendahnya prevalensi dari infeksi parasit salah satunya dipengaruhi oleh faktor musim. Pada musim kering larva cacing Strongyl di lingkungan banyak yang mati karena terpapar cuaca panas serta kekeringan dan akan berkembang baik pada musim basah sedangkan spesies lain seperti Trichuris menginfeksi pada stadium telur infektif (larva masih berada didalam telur) sehingga terlindungi oleh kerabang telur dan bertahan lebih lama di lingkungan.

Pemeliharaan domba di kabupaten Jember secara umum masih dilakukan secara tradisional, meskipun sebagian sudah dilakukan secara intensif seperti beberapa peternakan di kecamatan Gumukmas. Program pemberian obat cacing juga masih belum optimal, ini ditunjukkan dengan pemberian obat cacing yang tidak terjadwal dan terprogram pada peternak domba yang masih 
Awaludin et al.

ANIMPRO: Conference of Applied Animal Science Proceeding Series

memelihara domba secara tradisional. Hal tersebut menjadi faktor-faktor yang harus dievaluasi untuk pencegahan dan pengontrolan penyakit yang disebabkan oleh parasit gastrointestinal di masa mendatang. Awaludin, Nurkholis, \& Nusantoro (2019) pernah melaporkan bahwa tingkat infeksi parasit cacing pada saluran pencernaan domba dikarenakan kurangnya perhatian terhadap manajemen pemeliharaan dan program pengobatan cacing terutama pada peternak yang memelihara secara tradisional. Sanitasi kandang juga sering kurang diperhatikan sehingga menimbulkan potensi penyebaran parasit menjadi tidak terkendali.

\section{KESIMPULAN}

Parasit gastrointestinal yang teridentifikasi pada Domba Ekor Gemuk di kabupaten Jember adalah dari kelas nematoda dan protozoa. Parasit cacing kelas nematoda yang teridentifikasi adalah Strongyloides sp., Cooperia sp., Moniezia sp., Capillaria sp., dan Ostertagia sp sedangkan protozoa yang teridentifikasi adalah Eimeria sp. Prevalensi parasit gastrointestinal didominasi oleh Strongyloides sp. (20\%), Eimeria sp. (8\%), Moniezia sp. (8\%), Capillaria sp. $(4 \%)$, Cooperia sp. (2\%), dan Ostertagia sp. (2\%). Kejadian infeksi murni atau infeksi tunggal (single infections) sebanyak 95\% dan infeksi campuran (co-infections) sebanyak 5\%.

\section{DAFTAR PUSTAKA}

Awaludin, A., Nurkholis, \& Nusantoro, S. (2019). Gastrointestinal parasites of sheep in Jember district (East Java - Indonesia). $2^{\text {nd }}$ International Conference on Food and Agriculture 2019. Bali: IOP Conference Series: Earth and Environmental Science 411. doi:10.1088/17551315/411/1/011003

Awaludin, A., Hasanah, N., Nurkholis, Nusantoro, S., Kustiawan, E., \& Wahyono, N. D. (2021). Pencegahan helminthiasis pada ternak sapi di kelompok ternak Sido Makmur Jember. Jurnal IImiah Fillia Cendekia, 6(1), 1-5. Doi: 10.32503/fillia.v6i1.844

Ayaz, M., Raza, M., Murtaza, S., \& Akhtar, S. (2013). Epidemiological survey of helminths of goats in southern Punjab, Pakistan. Tropical Biomedicine, 30(1), 62-71. http://www.ncbi.nlm.nih.gov/pubmed/23665709

Chartier, C. \& Paraud, C. (2011). Coccidiosis due to Eimeria in sheep and goats, a review. Small Ruminant Research, 103(1), 84-92. https://doi.org/10.1016/j.smallrumres.2011.10.022

Hanafiah, M., Winaruddin, \& Rusli. (2002) Studi infeksi nematoda gastrointestinal pada kambing dan domba di rumah potong hewan Banda Aceh. Jurnal Sains Veteriner, 20(1): 15-19

Hassan, M. M., Hoque, M. A., Islam, S. K. M. A., Khan, S. A., Roy, K., \& Banu, Q. (2011). A prevalence of parasites in Black Bengals goats in Chittagong, Bangladesh. International Journal of Livestock Production, 2(4), 40-44.

Kumsa, B., Tadesse, T., Sori, T., Dugum, R., \& Hussen, B. (2011). Helminths of sheep and goats in Central Oromia (Ethiopia) during the dry season. Journal of Animal and Veterinary Advances, 10(14), 1845-1849. DOI: 10.3923/javaa.2011.1845.1849

Mavrot, F., Hertzberg, H., \& Torgerson, P. (2015). Effect of gastro-intestinal nematode infection on sheep performance: A systemic review and meta-analysis. Parasites and Vectors, 8(1), 111. https://doi.org/10.1186/s13071-015-1164-z

Perry, B. D., Randolph, T. F., McDermott, J. J., Sones, K. R., \& Thornton, P. K. (2002). Investing in animal health research to alleviate poverty. International Livestock Research Institute (ILRI), Nairobi, Kenya, p. 148

Pfukenyi, D. M., \& Mukaratirwa, S. (2013). A review of the epidemiology and control of gastrointestinal nematode infections in cattle in Zimbabwe. Onderstepoort Journal of Veterinary Research, 80(1), 1-12

Purwaningsih, P., Noviyanti, N., \& Sambodo, P. (2018). Infestasi cacing saluran pencernaan pada kambing kacang Peranakan Ettawa di kelurahan Amban kecamatan Manokwari Barat kabupaten Manokwari Provinsi Papua Barat. Jurnal IImiah Peternakan Terpadu, 5(1), 8-12. https://doi.org/10.23960/jipt.v5i1.p8-12

Rahayu, Y. G., Siregar, N., Thasmi, C. N., Herrialfian, Daud, R., Zuhrawati, Hamdan, dan 
Rasmaidar. (2018). Perbandingan konsentrasi progesteron selama siklus birahi pada Domba Waringin yang diinduksi PG2 $\alpha$ dan kombinasi PGF2 $\alpha$ dan GnRH. Jurnal IImiah Peternakan, 6(2), 101-105.

Sangma, A., Begum, N., Roy, B. C., \& Gani, M. O. (2012). Prevalence of helminth parasites in sheep (Ovis aries) in Tangail district, Bangladesh. Journal of the Bangladesh Agricultural University, 10(2), 235-244. DOI: http://dx.doi.org/10.3329/jbau.v10i2.14913

Sultan, K., Elmonir, W., \& Hegazy, Y. (2016). Gastrointestinal parasites of sheep in Kafrelsheikh governorate, Egypt: Prevalence, control and public health implications. Beni-Suef University Journal of Basic and Applied Sciences, 5(1), 79-84. https://doi.org/10.1016/j.bjbas.2015.12.001

Susilo, J. (2013). Dampak penyakit kecacingan pada performa ternak. Medik Veteriner Balai Veteriner Lampung. Infovet edisi Agustus, 42.

Talib, M., Matondang, R.H., \& Herawati, T. (2011). Breeding model for goats and sheeps in Indonesia. Workshop Nasional Diversifikasi Pangan Daging Ruminansia Kecil, 55-63.

Terefe, D., Demissie, D., Beyene, D., \& Haile, S. (2012). A prevalence study of internal parasites infecting Boer goats at Adami Tulu Agricultural Research Center, Ethiopia. Journal of Veterinary Medicine and Animal Health, 4(2), 12-16. https://doi.org/10.5897/JVMAH11.046

Thienpont, D., Rochette, F., \& Vanparijs, O. F. J. (1986). Diagnosing helminthiasis by coprological examination. Belgium: Janssen Research Foundation.

Urquhat, G. M., Armor, J., Duncan, J. L., Dunn, A. M., \& Jennings, F. W. (1987). Veterinary Parasitology. English Language Book Society / Longman.

Zeryehun, T. (2012). Helminthosis of sheep and goats in and around Haramaya, Southeastern Ethiopia. Journal of Veterinary Medicine and Animal Health, 4(3), 48-55. DOI: 10.5897/JVMAH12.0014 